\title{
Systematic Mapping of Methodologies Used for the Validation of Models and Scales Derived From e-SQ
}

\author{
Diana Faviola Olea-Flores ${ }^{1}$, Luis Cuautle-Gutiérrez ${ }^{2}$, Alejandra Aldrette-Malacara ${ }^{3}$, Marisol Reyes- Alcantar ${ }^{4}$ \\ ${ }^{1}$ Ph.D Student, Universidad Popular Autónoma Del Estado de Puebla (National Autonomous Popular University of Puebla) \\ México. \\ ${ }^{2}$ Faculty of Industrial and Automotive Engineering, Universidad Popular Autónoma del Estado de Puebla (National Autonomous \\ Popular University of Puebla), México. \\ ${ }^{3}$ Engineering Deanship, Universidad Popular Autónoma Del Estado de Puebla (National Autonomous Popular University of \\ Puebla) México. \\ ${ }^{4}$ Faculty of Industrial Engineering, Universidad Tecnológica de Puebla (Technological University of Puebla), México.
}

\begin{abstract}
ABSTRAC: Electronic Service Quality (e-SQ) is a topic that has been reviewed by several authors and, given the situation we live in, has become more relevant in the world; therefore, it is of vital importance to generate an effective measurement of the service being provided, which will allow companies to know the needs and expectations of their customers and how they evaluate the service received. This article considers an exploratory-descriptive research, which through a systematic literature mapping (MSL) reviews the methods and techniques that have been applied for the validity of the scales derived from e-SQ, thus generating a focused view of the methods applied in scientific research in the last five years. With the results obtained, a theoretical model for validating a scale is generated and proposed, which could be useful for researchers seeking to confirm and validate their scales or who are in the process of developing a research project.
\end{abstract}

KEYWORDS: e-SQ, measurement scales, exploratory factor analysis, confirmatory factor analysis, PLS-SEM

\section{INTRODUCTION}

Electronic service quality (e-SQ) is a concept that has been investigated in recent years by various authors. With the increase of internet sales, the quality of electronic service has become a determining factor of success for companies, since it represents one of the main sources of competitive advantage. Through a correct measurement of the quality of the electronic services offered, it is possible to know the customer's expectations and how customers perceive and evaluate the service delivered to them [1].

The e-SQ scale has been reviewed by various authors, who have tried to test and adapt the main scale proposed by Parasuraman and Zeithaml (2005) [2], in different contexts, using various methods and techniques for the validation of the assessment instruments. Measurement of these proposed scales and dimensions have been able to confirm their reliability and validity for the investigations carried out. Indicating the relevanceimportance and involves applying methods and correct techniques for validation to the scale derived generate a new e -SQ.

In the process of $\mathrm{d} I$ development of a measuring instrument, $\mathrm{s}$ and stresses the importance of validation as a process articulated in which after its validity is required transcend reliability, which is a condition or premise applied in any process of measurement in scientific studies and research [3]. Similarly to some authors such as [4]; [5] state that "effective measurement is the cornerstone of scientific research" [6].

The present article seeks to explore and conduct an analysis of the methods and techniques most applied (focal points) by researchers for the development and validation of their measuring instruments used for their scales derived from e-SQ and presented in the various investigations (last 5years); Through a systematic mapping of the literature, the results are expected to provide useful information for researchers who seek to generate, confirm and validate their scales derived from e-SQ, as well as researchers from other areas whose aim-objective is to generate an instrument measurement for the validation of your models or scales.

\section{LITERATURE REVIEW / FRAME OF REFERENCE}

2.1. e -SQ and the development of its scales

At the beginning of the 21 st century, the literature began to generate various works and investigations, with the objective of developing various scales to measure the perception of the quality of electronic services in order to generate a definition and measurement of the main determining factors and dimensions. for the perception of such quality-of electronic services [7]. Some authors such as Loicono, Watson and 
Goodhue, 2000; Barnes and Vidgen, 2003; Zeithaml, Parasuraman and Malhotra, 2000; Wolfinbarger and Gilly, 2003; Bauer, Hammerchmidt and Falk, 2006; among others, they propose the use of a general categorization of services itself that would serve as a structure to develop new models of quality of services based on the Internet [7].

In the development of the various scales that have been generated derived from e-SQ, it is relevant and fundamental to pay special attention to the process, method and technique that has been used to build, test and refine a scale. Some authors- As is the case of Zeithaml, Parasuraman and Malhotra (2000-2005 ) [8], pioneers on the subject who, taking the main scale of e-SQ, conceptualize, build, refine and test it, achieving in this process a multi-element scale (ESQUAL). In this process and for the development of e$S Q$, these authors indicate that as a first instance they delineated their domain through the step-by-step description of the process used in developing the scale to measure e-SQ (Fig. 1). It should be noted that, in addition to the existing literary review carried out in said process, and as part of the methodology used (step 2 suggested by the author), it presents a preliminary scale, which is composed of 121 elementsitems, contained in 11 dimensions of the quality of the electronic service that was reviewed with information obtained from two discussion groups, and whose process was refined both qualitatively and empirically through research. (Steps 2 to 5) with which they achieve a moderate scale, taking with it a replicable process and consisting: 1. Reliability analysis in which the items are grouped according to the conceptual dimension from which they were derived to continue with the elimination of items, this examining the correct correlations between the elements with the calculation of the alpha coefficient and items for total correlations by Dimension 2. With the information and result of the data from the previous step, item elimination is obtained-generated. 3. With the resulting items, an examination of dimensions is generated through an exploratory factor analysis; Likewise, by applying a principal component analysis and using the extraction and oblimin method (with Kaiser normalization) and the rotation method, this iterative process resulted in the final ES-QUAL scale, in which by means of a factorial analysis confirmatory (CFA), the factorial structure 4 could be evaluated in greater depth. With the previous examination, items are reassigned and the dimensions are restructured as deemed appropriate. For Zeithaml, Parasuraman and Malhotra (2000-2005) in the development of their scale and with the two stages of data collection, they found that it was necessary to generate two different scales ES-QUAL and E-Recs-QUAL, which are known as part and derived from the E-SQ scale and that have been basic and relevant as well as used-used-applied in various investigations and that were evaluated and refined through the same iterative process that was mentioned.

\subsection{Statistical methods for scale validation}

In the development process of scientific research it can be highlighted that among its main objectives is to generate knowledge, which can have a qualitative and/or quantitative approach, for which careful and systematic processes are applied. In research with a quantitative approach we can find that some of its characteristics are: systematic, controlled, orderly, critical confidence in the results and requires a process of several steps, which have the same importance to generate results that are valid and reliable. [9].

Likewise, [10] affirm that the quantitative research method is focused on the measurement and analysis of the variables to determine the result. Similarly, it analyzes the data numerically for which it uses various statistical techniques that are available in order to answer questions such as who, where, how, who, how much, when and what. Therefore, the definition of quantitative methods is "the explanation of a topic or phenomenon by means of the link of data whose form is numerical in order to be analyzed with the support of various mathematical methods and whose focus is statistical" [10].

\subsection{Definitions and Fundamental concepts used in the validation of scales}

For the development of research, it is necessary to determine a measurement instrument which is a technique or group of techniques that will allow us to assign a number that counts the expressions of a measurable construct only indirectly (Herrera, 1998). Therefore, it can be defined that research instruments are effective tools that help us in data collection [3].

For some authors such as [3] indicates that, for [11], measurement is a process that must be taken into account both to assess the theoretical and the empirical. In the empirical, it refers to observable responses, which can be through applied questionnaires, direct observation or responses generated through an interview. As for the theoretical, we find interest in concepts that are not observable (not directly measured). The measurement is directed and contemplates that relationship between indicators that generate observed responses and unobservable concepts.

Some authors such as [12] use and apply a descriptive analysis which is useful to show the data collected in the survey more clearly. Some premises that are considered essential to consider before starting the validity and reliability of the model, and that are required for the application of some techniques or methods, we find the descriptive analysis whose basic measure is the collection of information from quantitative data and show in a way more clear the collected data; similarly descriptive distribution statistics are used for large-scale test data. Some recommended tests of these statistics are the Normality Test with which we can determine if the data of the sample obtained is distributed in a normal way the data of a random variable within its mean and with a horizontal asymmetry as well as, within the ranges recommended (-1 
and +1 ). In the same way, it is recommended to consider the kurtosis itself, which indicates the height and sharpness of the central peak and whose shape is illustrated as a standard bell curve, the values considered for the kurtosis value, +1 indicates positive kurtosis while -1 indicates negative kurtosis [13]. With the above, we will be able to determine which techniques are the most appropriate for the reliability and validity analysis.

Among the main domains or characteristics of a measurement we find reliability and validity [11]. For [14], he affirms that reliability refers to the fact that when an object is measured several times (repeatedly) using the same instrument, it will always have the same results; It should be noted that reliability does not guarantee, nor is it synonymous with accuracy. So an instrument can be reliable but nevertheless not valid for a particular population or also in some cases it may be presented that the instrument has been manipulated in order to obtain certain results [3].

For their part, authors such as [13], indicate that, according to [15] they suggest that to improve the precision of the evaluation of the questionnaire data, suggests the reliability test with which the concept and affective value of the items are measured. Cronbach's Alpha is useful to measure the reliability and internal consistency of each item mentioned in Likert scale surveys (Gliem \& Gliem, 2003). Likewise, [13] affirm that reliability is the degree of reliability in which the measurement model can measure the expected latent constructs [16]. Reliability can be defined as the robustness or stability of the measurement obtained between two or more instruments. Therefore, there are 3 criteria for evaluating the reliability of a measurement model: 1) Internal reliability, 2) Reliability of the constructs and 3) Average variance extracted (AVE).

Table 1. Reliability Criteria

\begin{tabular}{ll}
\hline RELIABILITY & Criterion \\
\hline Internal reliability & $\begin{array}{l}\text { It is reached when Crombach's Alpha } \\
\text { is } 0.7 \text { or higher. }\end{array}$ \\
Construct & $\begin{array}{l}\text { It is the measure of reliability and } \\
\text { reliability }\end{array}$ \\
& $\begin{array}{l}\text { variables that represent a latent } \\
\text { construct. To achieve construct } \\
\text { reliability, a CR value } \geq 0.7 \text { is } \\
\text { required. } \\
\text { The mean variance extracted (AVE) } \\
\text { variance extracted } \\
\text { is the mean percentage of variation } \\
\text { explained by the items of a } \\
\text { construct. AVE } \geq 0.5 \text { is required. }\end{array}$ \\
\hline
\end{tabular}

Source: [13] with information from [17].

Regarding the validity of an instrument, [3] comments that a traditional definition used and commonly used in this regard is validity if it measures what it claims to measure. While, [18], indicates that the previous definition is incomplete, since an instrument will be valid if the degree of ownership of the inferences and interpretations as part of the results of a test and includes its social consequences, ethical, etc. Also [18] indicates that, the validity can be considerate as a unified concept, is considered a high value because it indicates to the how and why of the results of the test or questionnaire are employed and their consequences. Consequently [19], indicate that the validation of an instrument is not a definitive process since it requires constant empirical checks. Neither is it a dichotomous trait but rather one of degree, since it cannot be permanently affirmed that a generated test is valid, what can be affirmed is that said test presents certain degrees of validity for certain specific uses and for certain populations [3].

Likewise, [13] indicate that there are 2 types of validity tests for a measurement model:

Table 2. Types of validity tests

\begin{tabular}{|ll|}
\hline Validity & Requirements \\
validity & Convergent validity is achieved when all \\
the items in a measurement model are \\
statistically significant. This validity can \\
also be verified through the Average \\
Variance extracted (AVE). The value of \\
the AVE must be greater than or equal to \\
0.5 to achieve this validity and the \\
reliability of the construct (CR) must be \\
greater than the AVE. \\
AVE> 0.5 CR>AV \\
The Maximum Shared Squared Variance \\
(MSV) and the Average Squared \\
Validity \\
discriminant validity of the measure. The \\
results of the MSV and the results of the \\
ASV must be less than the AVE for \\
discriminant validity (Hamid et al., 2017) \\
MSV <AVE; ASV <AVE
\end{tabular}

Source: [13] with information from [17].

\subsection{Multivariate Techniques}

On the other hand, some of the multivariate statistical techniques that have been applied the most in various investigations by various authors for several decades are Exploratory Factor Analysis (EFA) and Confirmatory Factor Analysis (CFA). For some authors such as [20], they indicate that the EFA's main purpose is to define groups of variables (factors) that are highly correlated with each other. It is also used to reduce a large number of variables to a smaller number. In such a way that the EFA has two objectives: To exploratory establish an internal structure based on new factors or set of variables and 2 nd to reduce the number of them is to explain a phenomenon in detail.

While the CFA examines or evaluates the extent to which a set of theoretically ordered factors fits the data. Likewise, in this type of analysis a fundamental role is 
occupied by the researcher, who plays an important role since it is considered that the greater the knowledge of the problem, the greater the knowledge to formulate and test more concrete and specific hypotheses. In this analysis model, it is considered to establish a level of confidence in order to evaluate and assess whether the hypotheses that were raised are rejected or accepted. That is to say

The extent to which a set of theoretically organized factors fits the data is evaluated.

On the other hand, there are more recent techniques that, although they were developed for several decades, are considered an emerging technique and are currently more used. The purpose of PLS SEM is to test structural models and its main objective is predictive causal analysis, that is, the problems that are analyzed are complex even though the theoretical knowledge is scarce [21].

Likewise, as indicated by [22], PLS-SEM is based on the objective of the research, that is, if the objective is to predict the constructs, you recommend using PLS-SEM but if the objective is to test or confirm a theory, the most recommended technique is CB-SEM [23]. Similarly, [24] indicate that, PLS is a multivariate technique that allows comparisons between multiple dependent and multiple independent variables, so it is considered a SEM statistical method that it is based on variant design to complete multiple regression when specific problems such as lack of data (missing values), small study sample size, and multicollinearity are present [25].

Likewise, [23] indicate that, for (22) those who classify the first and second generation multivariate methods as indicated in Table 3.

Table 3. Classification of multivariate methods

\begin{tabular}{|lll|}
\hline Technique & $\begin{array}{l}\text { Mainly } \\
\text { (exploratory } \\
\text { predictive) }\end{array}$ & $\begin{array}{l}\text { Mainly } \\
\text { confirmatory } \\
\text { (evidential or } \\
\text { explanatory) }\end{array}$ \\
\hline $\begin{array}{l}\text { First generation tech } \\
\text { niques }\end{array}$ & Cluster analysis. & $\begin{array}{l}\text { Variance } \\
\text { analysis }\end{array}$ \\
\hline & $\begin{array}{l}\text { Exploratory } \\
\text { factor analysis }\end{array}$ & $\begin{array}{l}\text { Logistic } \\
\text { regression }\end{array}$ \\
\hline & $\begin{array}{l}\text { Multidimension } \\
\text { al scaling }\end{array}$ & $\begin{array}{l}\text { Multiple } \\
\text { regression }\end{array}$ \\
\hline & & $\begin{array}{l}\text { Confirmatory } \\
\text { factor analysis }\end{array}$ \\
\hline $\begin{array}{l}\text { Second generation } \\
\text { techniques }\end{array}$ & PLS-SEM. & CB-SEM. \\
\hline
\end{tabular}

Source: [23] with information [22]

\section{METHODOLOGY}

In order to identify the most significant and relevant methodologies and techniques that have been applied for the validation and refinement of models for the scales proposed in the literature derived from e-SQ, a systematic mapping of literature (Systematic Mapping, SMS) was performed, which is a methodology that allows us to have a broad overview of scientific knowledge, research trends and the results that have been generated and published, in order to categorize them [26].

The present research was developed applying the guidelines of the methodological proposal of [27], who consider the methodological proposal of Petersen, K.; Feldt R.; Mujtaba S. and M. Mattsson (2008) [28], to perform a systematic literature mapping and which consists of 5 essential steps:

1) Definition of research questions 2) Search for primary studies 3) Selection of articles applying inclusion and exclusion criteria 4) Classification of studies 5) Extraction and summary of data.

\subsection{Definition of the research questions}

In order to have a more detailed perspective of the subject under study and to be able to analyze the information (techniques and methodologies) mostly from e-SQ applied in the last 5 years, the following research questions are posed:

Q1 ¿How many published studies have been generated in the last 5 years in which a methodology for scale validation is applied?

Q2 ¿What methodologies (techniques-methods) have been applied to validate and refine the proposed models and scales derived from e-SQ in the last 5 years?

Q3 ¿What methodologies have predominated and prevailed in the validation and refinement of models and/or scales in the last 5 years?

\subsection{Search for primary studies}

According to the methodology used by Petersen et al., (28) in this step of searching for primary studies in the literary space and for the exercise of this study, first defining-defining the search terms or strings, which implies determining the keywords, which are derived from the research questions and which serve as a search engine for the various electronic databases, which in combination with Boléan operators ("AND" and "OR") obtained the following search terms: e$\mathrm{SQ}$, measurement scales, exploratory factor analysis, confirmatory factor analysis, PLS-SEM

Academic google search words: statiscal methods and techniques or analyze the e-SQ dimensions. The electronic databases considered for the present study are: Ebsco, Mendeley, Emerald and Google Scholar. The period considered for the search for studies covers from 2016 to 2021.

\subsection{Inclusion and exclusion criteria}

According to the methodology used by Petersen et al. the inclusion and exclusion (selection) criteria are used to exclude studies that are not relevant and that serve as support to answer the research questions. In terms of inclusion criteria, the following were considered: studies in English and Spanish, studies in which methodologies and techniques were applied and evaluated to validate and refine models and scales with their e-SQ dimensions, qualitative and quantitative 
studies carried out for the validation of scales and their dimensions, studies whose methodology helps to answer the research questions, and studies whose methodology helps to answer the research questions.

Exclusion criteria: duplicate articles or studies, studies whose title does not contain at least one keyword, articles in which the abstract does not mention applied methodology and related to the research topic (e-SQ), articles without availability of the full text. Articles whose design and research content do not present evidence of the application of scale validation methods.

\subsection{Execution of the search}

\subsubsection{Selection of Primary Studies}

For the selection of primary studies, the inclusion and exclusion criteria were applied to the studies that were located in the databases mentioned above and by means of the established search chain. To ensure the reliability of the information obtained, the test-retest process recommended by Kitchenham [29] was used, in which he proposes that the researcher perform a second extraction and which consists of a random selection of the primary studies to verify that the consistency of the data presented is as indicated and that the information recorded is reliable.

\subsubsection{Filtering of Results}

In the search process, a total of 3208 studies were obtained, leaving 918 when applying the first filter, which is the period established for the research and covers from 2016 to 2021; with the elimination of duplicate articles, 511 studies were obtained, when applying the next filter, articles with unavailable content and accepted languages were reduced to 219 , of which only 86 met the inclusion and exclusion criteria; In the content analysis review, a total of 25 were obtained as a result; therefore, to verify the consistency and concordance of the data obtained and to ensure the information recorded, the last test-test filter was applied, 10 randomly selected articles were taken and subjected to the second extraction, with which the information was confirmed, leaving 25 as the final result, which are the group of primary studies. Fig.1 Filtering of studies

Figure 1. Primary studies

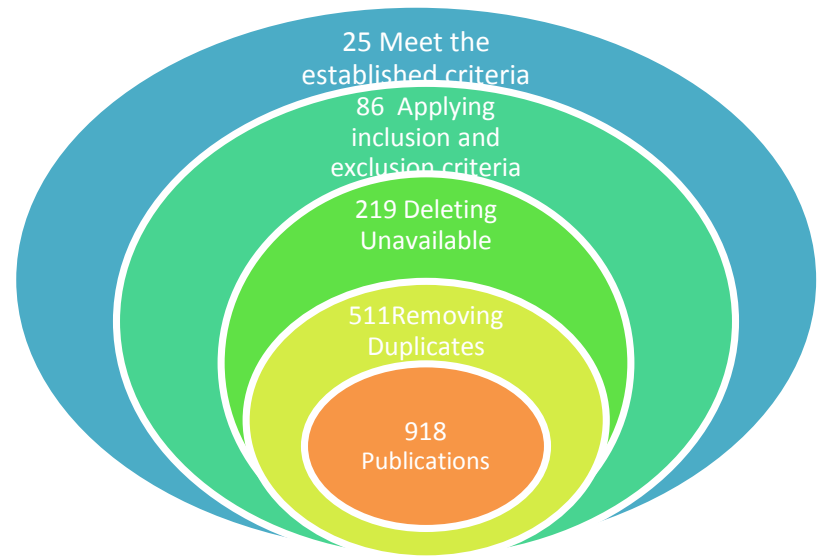

\subsubsection{Classification of studies}

In the selection of primary studies, they were categorized based on the research questions and the following categories were established: Year of Publication, Approach, Methods applied, Techniques applied.

\subsection{Data extraction}

The data extraction was carried out by the author individually, starting from the reading of each of the documents and completing the data corresponding to the category noted [27]. The information obtained was compiled in a spreadsheet generated in Excel considering the established categories.

\section{RESULTS}

As the last stage of the systematic mapping, the primary studies that were selected are shown and the research questions are answered.

Q1 ¿How many published studies have been generated in the last 5 years in which a scale validation methodology is applied?

Considering the study period from 2016 to 2021 and the criteria under which the research was evaluated; as indicated above at the beginning of the research and as part of the systematic mapping process, 3208 studies were initially found, of which 918 publications coincide with the search criteria, without considering whether the objective of the research is the verification of a model, relationship between variables, proposal of a new model, etc., so that when applying the corresponding filters, a total of 25 primary studies were obtained, which are distributed as shown in Figure 2. Table 4 confirms this information, since it is a concentrated or general inventory of the techniques generated per year.

Figure 2. Publications per year

\section{Articles published by year}

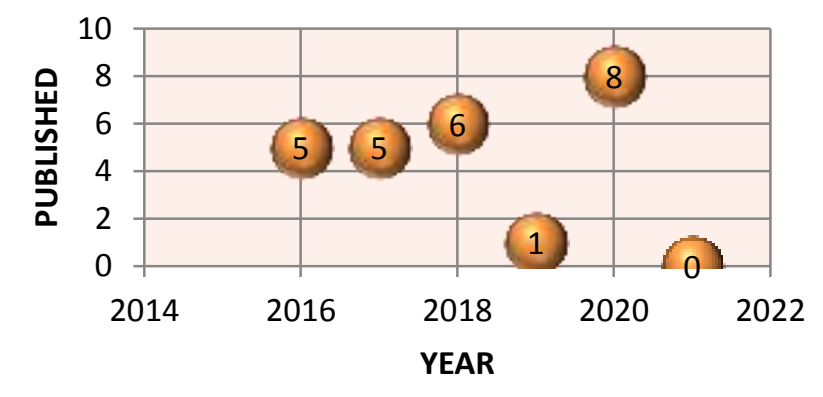

Source: Own preparation

Q2 ;What methodologies (techniques-methods) have been used to validate and refine the proposed models and scales derived from e-SQ in the last 5 years?

From the results obtained in Figure 3 shows the various methods that have been applied in the research in the period

Source: Own preparation 
established for the present study and that covers from 2016 to 2021, among the methods that have been applied are the Factor Analysis both Exploratory and confirmatory, principal component analysis, PLS, etc. Likewise, in the review of the selected articles, an inventory of the techniques that have been applied is made, and presented in Figure 4, which shows a general scenario with the breakdown by year, author, the techniques applied ( categorized according to the domain or characteristic to be measured, p/e descriptive analysis, reliability criterion, validity test, confidence indices. The above highlights that among the various techniques reviewed and applied by the authors, it is essential to consider the focus or objective of the research in order to determine the appropriate method and technique. Similarly, Table 4 shows a breakdown of the techniques used by author as well as the focus of each investigation; for reasons of space, the names of the techniques are abbreviated but are presented as a table attached to the figure for interpretation.

Figure 3. Methods applied

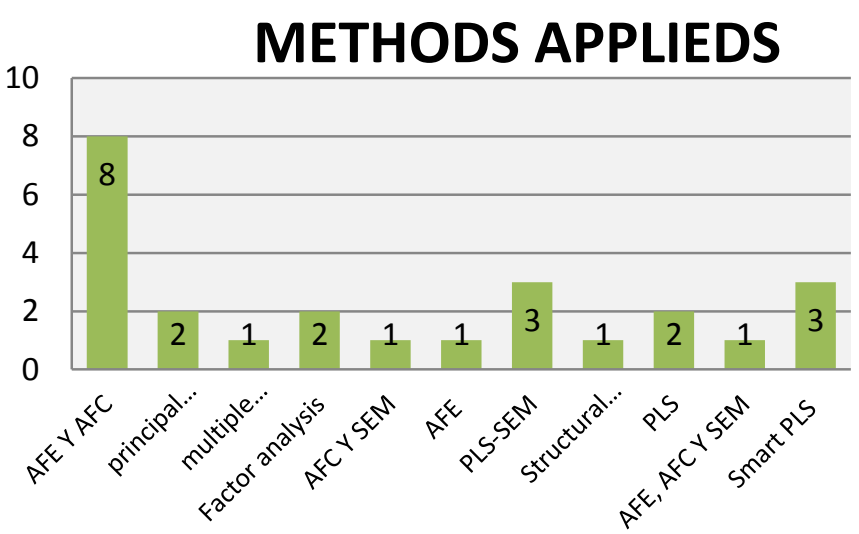

Source: Own preparation

Figure 4. General inventory

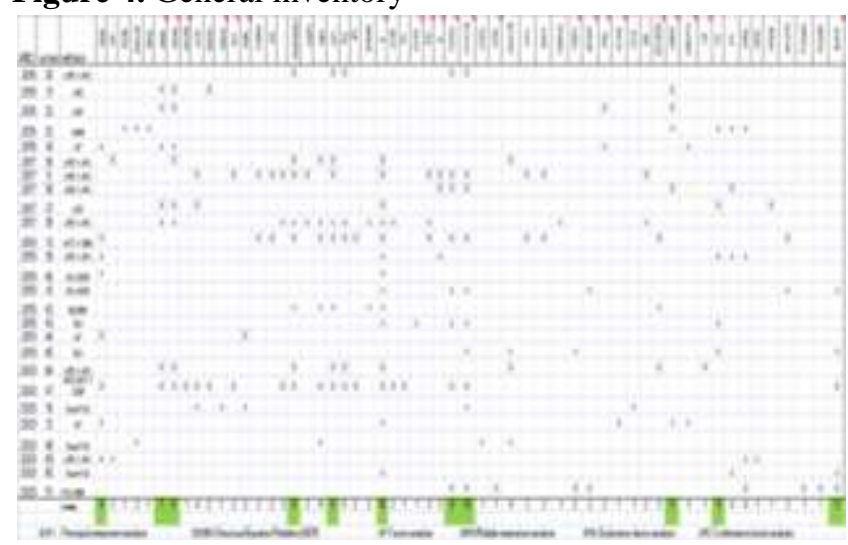

\begin{tabular}{|l|ll|}
\hline Descriptive Statistical Analysis & CONVERGENT \\
= AED & VALIDITY & \\
Pilot Test = PP & Cronbach's & Alpha \\
Normal Distribution Test = PDN & $=$ VCa & \\
Multicollinearity test $\quad$ (VIF) & Composite & \\
$=$ PMVIF & Reliability & (RC) \\
& $=$ VCRC & \\
\hline \hline
\end{tabular}

\begin{tabular}{|c|c|}
\hline 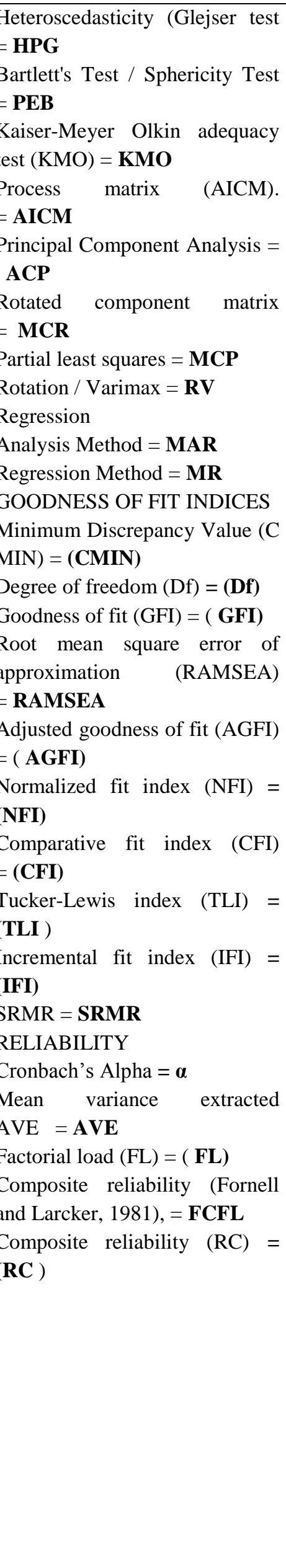 & 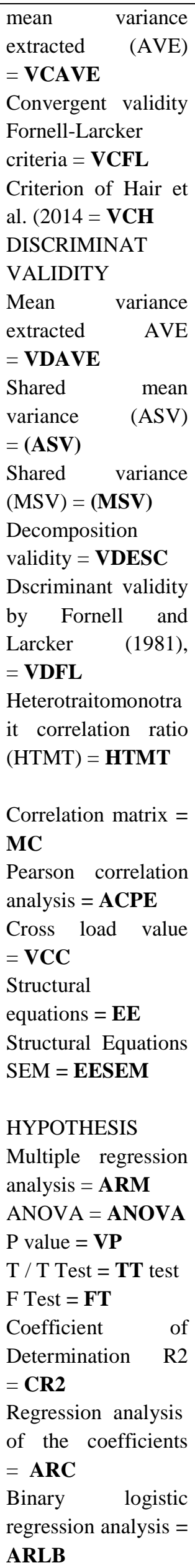 \\
\hline
\end{tabular}




\begin{tabular}{|l|l|}
\hline & Coefficient of Path = \\
CPATH \\
Test \\
Stone- Geisser (Q2) \\
= TSGQ2 \\
Root mean square \\
residual RSMR = \\
RSMR . \\
Bootstrapping \\
= BSTP \\
\hline
\end{tabular}

Source: Own preparation

Table 4. Techniques applied by author

\begin{tabular}{|c|c|c|c|}
\hline Year & Author & Method & Applicable Techniques \\
\hline 2116 & 30 & FEDCLD & 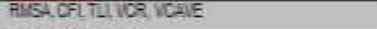 \\
\hline 2016 & 31 & AFE & PEA NMO, WC AFII \\
\hline 2016 & 32 & Fristipa Cunperet thayse & FEA KIO, IC AFI \\
\hline 2116 & 33 & Whtoplaregresugnenaijss & FOU PWW , APG , AVU, TI, FT, CFC \\
\hline 2916 & 34 & Fachorinalys & RED PEA WIO WD, AVOKL \\
\hline 2017 & 35 & AFEADAFC & PF, 610, RUISEI MF, CF a, WDUE \\
\hline 217 & 6 & AFEADAFC & 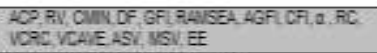 \\
\hline 2017 & 36 & AFADAEC & $a$, VCAC, VLAE, LRV ANOUAFT \\
\hline 2017 & 37 & Fring: Conprett trahse & 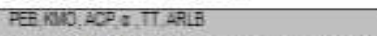 \\
\hline 2117 & 38 & AFADAF & 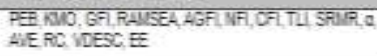 \\
\hline 2018 & 13 & ARtogla & 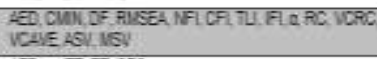 \\
\hline 2618 & 39 & AFANDAFC & $\mathrm{AED}, \mathrm{a}, \mathrm{T}, \mathrm{FT}, \mathrm{CF} 2$ \\
\hline 2418 & 40 & FISFEM & AEDa \\
\hline 2018 & 41 & P.SEIV & a, VCAC, VAUE, ATMT, CPATH, ISTP \\
\hline 2018 & 42 & 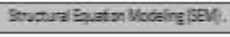 & 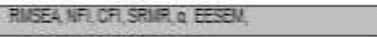 \\
\hline 2018 & 43 & PIS & 2, FCFL VCAC, VCAE, TI \\
\hline 2016 & 4 & Facter aratials & ADI UR \\
\hline 2019 & 45 & PIS & VCLE VDAE WDFL TT BSTP \\
\hline 2120 & 46 & AFtavere & 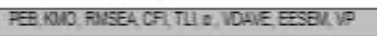 \\
\hline 2120 & 47 & AF, $\triangle F C$ CSONEV & 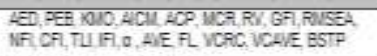 \\
\hline 2126 & 10 & SranfS.S & WOO WOP IR VLLIE WOO \\
\hline 2620 & 12 & Fecturavajey & AED , $a$, ACPE AFI AION \\
\hline 2020 & 48 & SranPS & PUF IFI VCI VOWE \\
\hline 2120 & 49 & AFAADAEC & AED, $P P, C R 2, A R C$ \\
\hline 2120 & 50 & Srantis & 2.FT BSTP \\
\hline 2020 & 51 & PLSTEV & $\begin{array}{l}\text { VCAC VCLEE VCH, VAF HTM, CR2 TSGC2 } \\
\text { FSIRR BSTP }\end{array}$ \\
\hline
\end{tabular}

Source: Own preparation

With the analysis performed, we found that the focus of the investigation is crucial to determine the appropriate method and technique to use. Authors such as [30] in their research indicate that their objective is to determine the relationship between the dimensions of e-SQ and user satisfaction using the model of disconfirmation theories, for which they choose to use Confirmatory Factor Analysis (CFA) with which validates and evaluates the data collected from the survey applied to a population of 320 students from 5 higher education institutes, and later, through the support of AMOS 21 , to make the model and find the relationship between the variables indicated above and thus arrive at the final model. Similarly [46] in their work whose objective was to find the relationship between the e-SQ dimensions and user satisfaction applied the AFC for university students as a means, their model indicates acceptable values and the structural equation model (SEM) confirms the positive impact between the dimensions indicated. For his research, [35] initially carried out a pilot test and subsequently used AFA with the support of SPSS 20 and the AFC with AMOS 20 to analyze the data. In his study, [31] used an AFA as one of the techniques he applied, to examine the validity of the instrument, he used the KMO and Bartlett's test of sphericity respectively, and as a method for extracting factors he used the rotated component matrix, which indicates the dimensions proposed for e-SQ.

Q3 iWhat methodologies have predominated and prevailed-in the validation and refinement of models and / or scales in the last 5 years?

With the general inventory made, it is possible to validate how the methods and techniques have been applied in the year in which they were used; therefore, a balance is highlighted in the methods of exploratory and confirmatory Factor Analysis with PLS methods applied, and this can be confirmed in Figure 3: Descriptive Statistical Analysis=AED which was applied by 8 authors for their research being in the initial process where they apply it, Kaiser-Meyer Olkin Matching Test $(\mathrm{KMO})=\mathrm{KMO}$ as a sample adequacy test likewise was applied by 8 authors followed by Bartlett's Test/Test of Sphericity Test $=$ PEB applied in 7 studies. As for reliability indices, the root mean square error of approximation $($ RAMSEA) $=$ RAMSEA and comparative fit index $(\mathrm{CFI})=(\mathrm{CFI})$ were applied in 8 studies. For reliability assessment Cronbach's $\alpha=\alpha$ was applied in 14 studies and Composite Reliability $(\mathrm{CR})=(\mathrm{CR})$ in 11 . For convergent validity tests the average variance extracted $(\mathrm{AVE})=$ VCAVE was applied in 10 studies and for discriminant validity the average variance extracted AVE = VDAVE was applied in 4 studies. For hypothesis testing the Multiple Regression Analysis $=$ MRA, $\mathrm{T}-$ Test $=\mathrm{TT}$ and Bootstrapping = BSTP were applied as support for testing in 5 studies respectively. These data can be seen in Figure 4 and Table 4.

\section{CONCLUSIONS}

With the analysis performed on the results we can highlight that the techniques that have been applied has a very clear trend which indicates that until before 2018 the techniques that can be found in most of the researches were used are the first generation ones among the main ones AFE and AFC as well as to Principal Component Analysis; it is from 2018 where it is observed to see the inclination of researchers to use PLS techniques either SEM or Smart-SEM which are categorized as second generation techniques or methods and that thanks to the Software it uses, it allows to apply various techniques without having to consider some relevant characteristics that are required in the first generation methods. It is worth mentioning that the Factorial techniques will continue to be a support in the validation of scales since sometimes, in spite of the use of the Software, it is necessary to confirm the results with some alternative techniques to the Software used.

Likewise, from the analysis carried out, the following model is proposed (Figure 5) which presents the suggested sequence for the reliability and validity of a model or scale; and which is designed considering the methodologies used by the different authors and according to the literature reviewed; It 
should be noted that given the wide range of techniques that exist, the model is generated seeking to narrow down the techniques and approximate the sequence used in various investigations, so it is important to emphasize that for its application, it is essential to consider first of all, what is the objective and focus of the research in which it is to be applied and thus confirm whether the proposed model is compatible with the required research. As a positive aspect of the model we can point out that the use of the model will allow researchers in different areas, from the beginning of the research, to know the sequence to follow for the validation of their model. It can also be used to confirm the sequence that has been applied in completed research.

Figure 5. Theoretical model to validate a scale

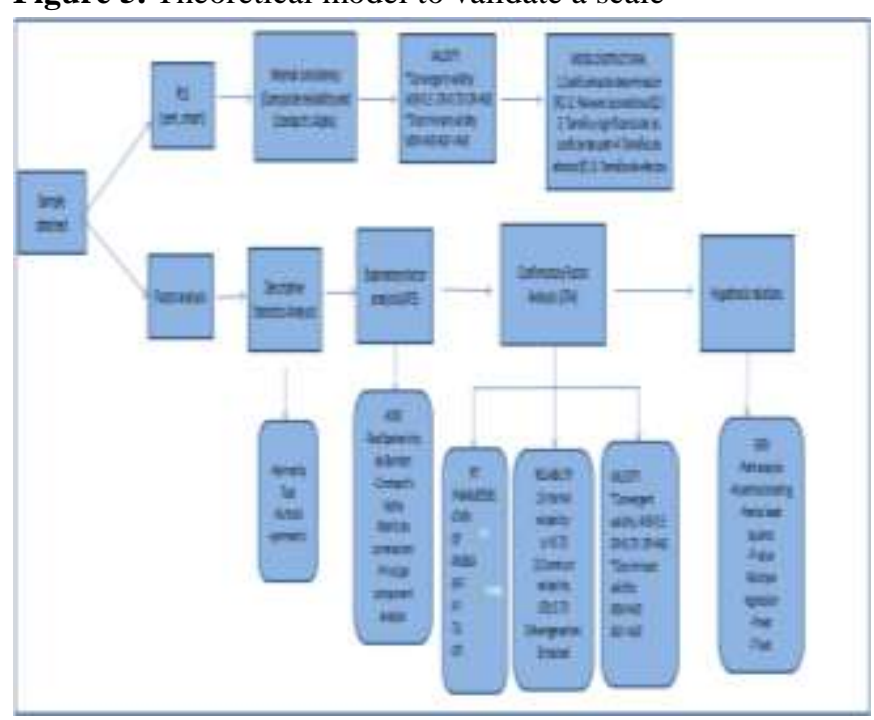

Source: Own preparation

\section{REFERENCES}

1. Alanezi, M. A., \& Sellami, A. (2019). A Unified Framework for Measuring E-Service Quality. Engineering, Technology \& Applied Science Research, 9(3), 4249-4254.

2. Parasuraman A, Zeithaml VA, and Malhotra A. (2005). E-S-QUAL: A multiple-item scale for assessing electronic service quality. Journal of Service Research, 7(3), 213-233.

3. Soriano, A. M. (2014). Design and validation of measurement instruments. Dialogues 14, 19-40.

4. De Vellis, R.F. (2003), Scale Development: Theory and Applications, 26, 2nd ed., Sage Publications, Thousand Oaks, CA

5. Slavec, A. and Drnovšek, M. (2012), “A perspective on scale development in entrepreneurship research", Economic and Business Review, 14(1), 39-62

6. A Kumar, Bhawna Anjaly, (2017) "How to measure post-purchase customer experience in online retailing? A scale development study", International Journal of Retail \& Distribution Management,45(12),1277-1297
7. Al.dweeri R. (2011) The Quality of Electronic Services as a competitive strategy. Model of analysis of its components and effects on satisfaction and loyalty. [Ph.D. dissertation]. Málaga, SPICUM. 2011.

8. Zeithaml VA, Parasuraman A, Malhotra A. A (2000) Conceptual framework for understanding eservice quality. Implications for future research and managerial practice, Marketing Science Institute Cambridge, Massachusetts. 2000, 1-46.

9. Salazar, Z., y Prado, J., (2013), Importance of planning for data collecting: lessons from a research experience 2013.

10. C Hongdiyanto, M Padmalia, GG Gosal (2020), The influence of e-service quality and e-recovery towards repurchase intention on online shop in Surabaya: the mediating role of customer loyalty, DeReMa (Development of Research Management): Journal Management, 15(2).

11. Carmines, E. y Zeller, R. (1987). Reliability and Validity Assessment. USA: Sage

12. AP Selamat, Yahy Tay (2020). The Impact of Online Retail Service Quality on Customer Satisfaction, journal of Technology Management and Technopreneurship, 08(2020) 32-51

13. O Dastane, MI Bin Md Jalal (Omkar Dastane, Muhammad Ifwan Bin Md Jalal \& Karthik Selvaraj (2018), Assessment of Extended E-S-Qual Model in an M-Commerce Setting. International Journal of Management, Accounting and Economics, 5 (12).

14. Babbie, E. (2010). The Practice of Social Research. California: Wadsworth

15. Tavakol, M., \& Dennick, R. (2011). Making sense of Cronbach's alpha, International Journal of Medical Education (2), 53-55.

16. Awang, Z. (2015). SEM made simple: A gentle approach to learning structural equation modeling. MPWS Rich Publication Sdn. Bhd

17. Ahmad, S., Zulkurnain, N. N., \& Khairushalimi, F. I. (2016). Assessing the Validity and Reliability of a Measurement Model in Structural Equation Modeling (SEM), British Journal of Mathematics \& Computer Science, 15(3), 1-8.

18. Messick, S. (1996). Standards-based score interpretation: Establishing valid grounds for valid inferences. Washington DC: Government Printing Office

19. Alfaro, K. y Montero, E. (2013). Application of the Rasch model in the psychometric analysis of a diagnostic test in mathematics, Digital Journal Mathematics, Education and Internet 13(1).

20. Méndez, C., y Rondón, M., (2012) (Carolina Méndez Martínez1 Martín Alonso Rondón Sepúlveda. Introduction to exploratory factor analysis. Rev. Colomb. Psiquiat, 41(1). 
21. Lévy, J. y Varela, J. (2006). Modeling with Covariance Structures in Social Sciences. España, Madrid: Editores Netbiblo

22. Hair, J., Hult, G., Ringle, C. y Sarstedt, M. (2017). A Primer on Partial Least Square Structural Equation Modeling (PLS-SEM). Estados Unidos, California: Sage.

23. Martínez, M., y Fierro, E., (2018),. Application of the PLS-SEM technique in Knowledge Management: a practical technical approach, $8(16)$.

24. Setiawan, S., \& Jaolis, F., (2018). Analysis antara e-service quality, online perceived value eloyalty dalai konekes e-commerce bukalapak, Publication Petra

25. Jogiyanto. (2009). Konsep \& aplikasi PLS untuk penelitian empiris. BPFE Yogyakarta.

26. Carrizo, D., \& Rojas, J., (2017). Methodologies, techniques and tools in requirements engineering: a systematic mapping. Ingeniare. Revista chilena de ingeniería, 26(3), 473-485

27. Monroy, M., Arciniegas, J., y Rodríguez, J., (2016). Software Architecture Recovery: A Systematic Mapping Study. Information Technological, 27(5), 201-22.

28. Petersen, K.; Feldt R.; Mujtaba S. y M. Mattsson, Systematic Mapping Studies in Software Engineering, 12th International Conference on Evaluation and Assessment in Software Engineering (EASE), 1-10.

29. Kitchenham, B., \& Charters, S. (2007). Guidelines for performing Systematic Literature reviews in Software Engineering. Engineering.

30. Iham, T., Ahmad, M., Kamil \& Mustapha, E., \& Jebur, Hamid. (2016). Measurement Model of eSQ Dimensions and Users' Satisfaction in Malaysian IHL.

31. OS Ting, MSM Ariff, N Zakuan, Z Sulaiman and MZM Saman. (2016). E-Service Quality, ESatisfaction and E-Loyalty of Online Shoppers in Business to Consumer Market; Evidence form Malaysia IOP Conf. Ser.: Mater. Sci. Eng. 131 012012.

32. M Askari, M Kazempoor, HR Saedi (2016). Measuring E-Service Quality from the Customers' Perspective: An Empirical Study on Banking Services, Journal of Marketing and Consumer Research. An International Peerreview (24).

33. As'adahullah Khairul Alam and A Prasetio(2016). The Effect of E-Service Quality toward Customer Satisfaction: PlayStation Store. International Journal of Science and Research (IJSR), 6(7).

34. Zehira, C., \& Narcıkarab, E.,(2016). E-service quality and e-recovery service quality: Effects on value perceptions and loyalty intentions. Procedia - Social and Behavioral Sciences (229) 427 - 443.

35. SE Hahn, B Sparks, H Wilkins, \& X Jin (2017). E-service quality management of a hotel website: a scale and implications for management, Journal of Hospitality Marketing \& Management, 26(7), 694-716.

36. Ali, M., Asmi, F., Rahman, M., Malik, N. and Ahmad, M. (2017) Evaluation of E-Service Quality through Customer Satisfaction (a Case Study of FBR E-Taxation). Open Journal of Social Sciences, 5, 175-195.

37. Fan Lh, Gao L, Liu X, Zhao Sh, Mu Ht, et al. (2017) Patients' perceptions of service quality in China: An investigation using the SERVQUAL model. PLOS ONE 12(12).

38. M Akin (2017), A Research on Measuring EService Quality in E-Retailing RMBR International Review of Management and Business Research, Vol. 6(1).

39. Sari, N., \& Yuniarti, Y. (2018). Analysis of go jek e-service quality and its effect on customer satisfaction in jambi city. Journal of business studies and management Review, 2(1), 16-20.

40. MC Minimol, K Kakkanad (2018) E-service quality and perceived value as predictors of customer loyalty towards online supermarkets, Asian Social Science, 14(3).

41. F Sjahroeddin (2018) the Role of ES-Qual and Food Quality on Customer Satisfaction in Online Food Delivery Service. Industrial Research Workshop and National Seminar, (9).

42. L Suhaily, Y Soelasih (2018). How e-service quality, experiential marketing, and price perception to make repurchase intention on online shopping. The International Journal of Business Management and Technology, 2(3).

43. S Setiawan (2018). Analysis antara E-service Quality, Online Perceived Value dan E-loyalty dalam Konteks E-commerce Bukalapak. Jurnal Strategi Pemasaran, 5(2).

44. KS Greeshma (2019). Impact of e-service quality of online shopping on customer loyalty intention: a case of puthur gramapanchayath, Thrissur International Journal of Engineering Applied Sciences and Technology, 4(5), 274-279

45. S. Kosasi, Vedyanto and I. D. Ayu Eka Yuliani, Boosting E-Service Quality through IT Service Management of Online Stores, 6th International Conference on Electrical Engineering, Computer Science and Informatics (EECSI), Bandung, Indonesia, 247-252.

46. ITI Al-Nuaimi, TM Mahmood, OW Khalid Othman \& Ammar, A., (2020). An Integrated Model of the Relation between E-Service Quality 

and User Satisfaction in IHL. Journal of Physics: Conf. Ser. 1529042072

47. Ahmed, R. R., Romeika, G., Kauliene, R., Streimikis, J., \& Dapkus, R. (2020) ES-QUAL model and customer satisfaction in online banking: evidence from multivariate analysis techniques. Oeconomia Copernicana, 11 (1), 5589

48. Rahahleh, A., Al-Nsour, S., Moflih, M., Alabaddi, Z., Al-nassar, B \& Al-Nsour, N. (2020). The influence of electronic service quality on relationship quality: Evidence from tourism industry. Management Science Letters, 10(12), 2759-2768.

49. M.Surekha (2020) E-Service Quality \& Customer Satisfaction A Comparative Study of Private \& Public Sector Banks. Journal of Xi'an University of Architecture \& Technology. 10(3),. 4414-4423.

50. Ivastya, R., \& Fanani, Z., (2020). The Impact of E-Service Quality on E-Satisfaction and Implications on B2C shopee.com the online Repurchase: A case study of Indonesia. I. J. Of Advances in Scientific Research and Engineering-IJASRE, 6(7), 1-9.

51. Raza, A., Rather, R.A., Iqbal, M.K. and Bhutta, U.S. (2020), An assessment of corporate social responsibility on customer company identification and loyalty in banking industry: a PLS-SEM analysis, Management Research Review, 43(11), 1337-1370. 